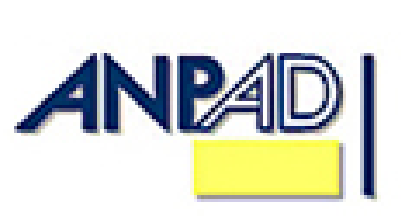

Disponível em

http://www.anpad.org.br/rac

RAC, Curitiba, v. 14, n. 4, art. 6,

pp. 670-683, Jul./Ago. 2010

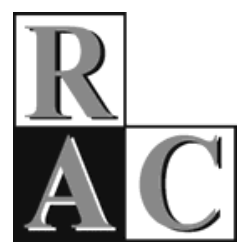

\title{
Ser ou não Ser Favorável às Práticas de Diversidade? Eis a Questão.
}

\author{
To be or not to be Favorable Towards Diversity Practices? This is the Question
}

Jamille Barbosa Cavalcanti Pereira * Doutora em Administração de Empresas pela Universidade Presbiteriana Mackenzie. Professora na Universidade Presbiteriana Mackenzie, São Paulo/SP, Brasil.

Darcy Mitiko Mori Hanashiro Pós-doutora em Administração pela Alliant International University, Estados Unidos. Professora na Universidade Presbiteriana Mackenzie, São Paulo/SP, Brasil.

* Endereço: Jamille Barbosa Cavalcanti Pereira

Universidade Presbiteriana Mackenzie. Rua da Consolação, 930, Bairro Consolação, São Paulo, SP. 01302-907. E-mail: jamillebc@uol.com.br

Copyright (C) 2010 RAC. Todos os direitos, inclusive de tradução, são reservados. É permitido citar parte de artigos sem autorização prévia desde que seja identificada a fonte. 


\title{
RESUMO
}

Práticas de diversidade vêm ganhando relevância crescente nas organizações brasileiras. No entanto, o campo teórico no Brasil não tem acompanhado esse desenvolvimento. A literatura corrente expressa a prevalência na identificação e discussão dessas práticas, baseando-se no princípio de que elas trazem resultados positivos às organizações. Contudo, essa concepção de natureza utilitarista omite subjetividades inerentes aos atores sociais, pertencentes aos grupos de identidade, considerados não dominantes no ambiente organizacional - os diversos - e aqueles que, tradicionalmente, constituem os dominantes. Esse ensaio visa discutir as atitudes desses dois grupos diante das práticas de diversidade, propondo um modelo teórico composto por quatro dimensões teóricas: atitudes de aceitação com base na justiça social, atitudes de aceitação com base na obtenção de ganhos, atitudes de rejeição com base na discriminação reversa e as atitudes de rejeição com base no receio ao estigma. Acreditase que o entendimento dessas atitudes venha a contribuir para o avanço em direção a uma teoria de diversidade, além de trazer uma visão de que a prática eficaz de diversidade nas organizações implica compreender a visão dos diferentes stakeholders envolvidos por elas.

Palavras-chave: diversidade; atitudes diante da diversidade; gestão da diversidade.

\begin{abstract}
The relevance of diversity practices has been growing in Brazilian organizations. Nevertheless, the theoretical field in Brazil has not followed this practical development. The current literature expresses the prevalence in the identification and discussion of these practices, based on the belief that diversity always brings about positive results for the organization. However, this utilitarian approach neglects intrinsic subjectivity inherent to different social actors: someone who belongs to an identity group which is not considered dominant in the organizational setting (minority) and those who are traditionally considered the dominant group (majority). This essay aims to discuss the attitudes of these two groups towards diversity practices, proposing a theoretical model made up of four theoretical dimensions: acceptance attitudes based on social justice, acceptance attitudes based on obtaining gains, rejection attitudes based on beliefs in reverse discrimination, and rejection attitudes due to concerns about stigma. The understanding of these attitudes can contribute to the development of new approaches in diversity studies, in addition to brining a vision that an effective diversity practice in organizations means understanding the vision of the different stakeholders involved in them.
\end{abstract}

Key words: diversity; attitude towards diversity; diversity management. 


\section{INTRODUÇÃO}

A sociedade se vai tornando mais heterogênea. Com isso, gestão bem sucedida de uma força de trabalho diversa constitui-se um dos desafios importantes para os líderes organizacionais. Esse desafio não reside na heterogeneidade da força de trabalho em si, mas na habilidade dos gestores em compreender a dinâmica da diversidade (Mor Barak, 2005).

A diversidade constitui fenômeno global que desafia modelos de gestão de pessoas que, tradicionalmente, valorizavam a cultura organizacional uniforme. Durante quase mais da metade do séc. $\mathrm{XX}$, era esperado e desejado que o perfil da classe trabalhadora fosse homogêneo no sentido de não haver diferenciação de pensamento, no jeito de ser e de agir. "Os trabalhadores, sob a concepção do Taylorismo e do Fordismo, eram similares, pois agiam sob o mesmo modelo e as suas diferenças eram ignoradas” (Bond \& Pyle, 1998, p. 253).

A expansão e mobilização geográfica das organizações que justificaram, em grande parte, o aumento da heterogeneidade demográfica das organizações no final do século $\mathrm{XX}$, passaram a exigir mais flexibilidade para lidar com as diferenças. No entanto, constata-se que a perspectiva de resistência, caracterizada pela negação, oposição ou manipulação em relação à diversidade é bastante ativa e presente nas organizações (Nkomo \& Cox, 1986).

Lidar com as diferenças implica valorizar o hibridismo cultural, em que similares e dissimilares possam conviver lado a lado. E isso significa para as organizações não apenas introduzir práticas de diversidade que enalteçam o valor das diferenças e meios de lidar com elas, mas conseguir que os seus empregados sejam envolvidos com elas (Ivancevich \& Gilbert, 2000). Nesse sentido, torna-se necessário conhecer como as pessoas reagem a essas práticas.

Há quem defenda a ideia de que a diversidade é positiva para o desenvolvimento das organizações, por se entender que ela aumenta o acesso a novos segmentos no mercado, eleva o moral, incrementa a criatividade e a produtividade dos indivíduos (Cox, 1991; Eron, 1995; Thomas \& Ely, 1996). Do ponto de vista dos negócios, a diversidade "conduz a uma vantagem competitiva" (Cox \& Blake, 1991, p. 45). Apoiadas por essa lógica, algumas organizações vêm desenvolvendo, desde algum tempo, iniciativas como estas: workshops, treinamentos e programas de sensibilização para a redução de preconceito e discriminação, aumento de contratação e de promoção de pessoas pertencentes a grupos tradicional e, historicamente, sub-representados, em termos de recursos, poder e status (Wetling \& Palma-Rivas, 2000)

Sob outra perspectiva, há quem defenda que as práticas de diversidade são inócuas, uma vez que ainda pouco se sabe do seu impacto na produtividade ou na lucratividade das empresas (Holzer \& Neumark, 2000; Kochan et al., 2003), bem como nos próprios indivíduos para os quais elas são designadas. Em países onde existe uma tradição nas práticas de diversidade, não há unanimidade de aceitação delas entre os indivíduos envolvidos, de alguma forma, com tais práticas (Beaton \& Tougas, 2001). No Brasil, com base na literatura pesquisada, há carência de estudos dessa natureza (Hanashiro \& Godoy, 2004a).

Conhecer a avaliação ou o posicionamento dos indivíduos em relação às situações diversas torna-se possível, a partir do estudo das atitudes, que revelam algumas vantagens. O conhecimento das atitudes de uma pessoa em relação a determinados objetos permite fazer inferências acerca de seu comportamento (Fazio \& Williams, 1986; Fishbein \& Ajzen, 1975).

As atitudes que as pessoas apresentam diante dos eventos que vivenciam podem tanto aproximá-las como distanciá-las deles (Lima, 2000). Dessa forma, entender as atitudes das pessoas, no tocante à diversidade, constitui aspecto essencial para compreender a subjetividade subjacente às políticas e práticas que envolvem a diversidade. Identificando essa lacuna, o objetivo deste ensaio é discutir as atitudes dos grupos não dominantes (diversos) e dominantes diante das práticas de diversidade. $\mathrm{O}$ entendimento das atitudes desses diferentes grupos de interesse contribui para o desenvolvimento de 
uma gestão da diversidade mais efetiva e integrada aos interesses e necessidades dos diferentes stakeholders. Os stakeholders, neste ensaio, são entendidos como sendo distintos grupos de interesse que, direta ou indiretamente, são beneficiados ou não e que têm o potencial de afetar as práticas de diversidade desenvolvidas pelas organizações.

\section{ATITUDES: CONCEITO E DEFINIÇÕES}

O termo atitude é amplamente utilizado na Psicologia (Allport, 1935; Eagly \& Chaiken, 1993; Rokeach, 1968). Indica a orientação seletiva e ativa do homem diante de uma situação ou de um problema qualquer (Abbagnano, 1982). Quando se diz que uma pessoa tomou uma atitude, entende-se que ela adotou determinada posição que não é neutra; ela utilizou-se de um julgamento avaliativo sobre algo, sobre alguma coisa ou sobre alguém. Esse julgamento pode ser favorável ou desfavorável, de fraca ou forte intensidade, ativado de imediato da memória ou de forma remota (Lima, 2000).

A atitude também se refere a um estado mental e neurológico de prontidão, organizado por meio da experiência e capaz de exercer uma influência ou dinâmica sobre a resposta do indivíduo a todos os objetos e situações a que está relacionada (Allport, 1935). Ou ainda, uma organização relativamente duradoura de crenças acerca de um objeto ou situação que predispõem uma pessoa a responder de uma determinada forma (Rokeach, 1968). Trata-se, portanto, de um estado mental que antecede a ação e que pode ou não determiná-la.

Após um trabalho de análise e sistematização da vasta literatura sobre o termo atitude, Eagly e Chaiken (1993) consagraram a definição dele, como sendo um construto hipotético e não diretamente observável. Segundo esses autores, a atitude refere-se a uma variável latente explicativa da relação entre a situação em que as pessoas se encontram e o seu comportamento. Constitui-se, ainda, de uma inferência dos processos psicológicos internos de um indivíduo feita a partir da observação dos seus comportamentos (verbais ou outros) ou de simplesmente uma tendência psicológica, entendida esta como estado interior, com alguma estabilidade temporal (Lima, 2000). Dessa perspectiva compreendese que as atitudes são construtos que só podem ser conhecidos quando manifestos.

As manifestações das atitudes ocorrem por meio de três respostas avaliativas psicológicas: a cognitiva, a afetiva e a comportamental, que podem agir sozinhas ou pela combinação entre elas. Dizse que um indivíduo adota atitude com base cognitiva, quando ele se justifica por meio de uma apreciação do objeto, baseado em pensamentos, em ideias, em opiniões e em crenças sobre ele (Aronson, Wilson, \& Akert, 2002).

Neste artigo, as atitudes referenciadas correspondem às cognitivas, visto que a intenção foi explorar as ideias e crenças que os indivíduos, membros de grupos não dominantes ou dominantes, possuem sobre as práticas de diversidade.

\section{As Funções das Atitudes}

Por que os indivíduos adotam e mantêm determinadas atitudes? O estudo sobre as funções das atitudes tenta responder a essa pergunta. Entre as teorias que apresentam razões para esse fim destacam-se a motivacional e a cognitiva. Sob a perspectiva da primeira dessas teorias, defende-se que, por trás das atitudes dos indivíduos, se encontram razões motivacionais de cunho utilitário ou simbólico (Katz, 1960). As atitudes serão baseadas em motivos utilitários, quando o indivíduo maximiza recompensas sociais e minimiza punições, ou seja, quando ele avalia os custos e benefícios que pode obter, ao posicionar-se contra alguma coisa ou a favor dela. Por outro lado, as atitudes terão razões motivacionais simbólicas, quando o indivíduo quer reforçar valores e a sua identidade enquanto sujeito, protegendo-se de conflitos internos e externos e preservando a sua imagem. 
Á luz da teoria cognitiva, as pessoas tomam atitudes para evitar desconfortos e ansiedades causadas pela incerteza, pela indefinição ou conflito de ideias em torno do objeto da atitude (Lima, 2000). Sob essa perspectiva as atitudes são explicadas para satisfazer uma função cognitiva. Dois são os princípios que convergem a essa teoria: o princípio do equilíbrio de Heider (1958) e o da redução da dissonância cognitiva de Festinger (1957).

O princípio do equilíbrio (Heider, 1958) se refere à forma como os indivíduos articulam diferentes percepções e atitudes sobre o mesmo objeto. Diante do mesmo objeto, a pessoa pode ter diferentes atitudes; porém isso não é o ideal, pois essa situação gera tensão. As situações organizadas de uma forma equilibrada seriam as mais estáveis e resistentes à mudança, mantendo uma tendência à constância das posições cognitivamente mais simples.

O princípio da redução da dissonância cognitiva (Festinger, 1957) defende a ideia de que os aspectos psicológicos que compõem as atitudes (cognitivo, afetivo e comportamental) precisam ser consistentes. Festinger (1957) postula que um estado de dissonância cognitiva ocorre quando não há coerência entre atitudes tomadas e sentimentos, pensamentos e opiniões ou comportamentos expressos. Essa é uma situação considerada psicologicamente desagradável, consistindo em motivação e ativação do organismo no sentido da redução ou da eliminação da dissonância. Vale ressaltar que nem todas as cognições incompatíveis produzem dissonância nos indivíduos.

Para reduzir a dissonância Festinger (1957) propõe o aumento do número ou da importância das cognições consoantes e/ou na diminuição do numero ou da importância das cognições dissonantes. Desse modo, o processo de redução da dissonância apresenta-se como exemplo de como as atitudes influenciam o processamento da informação, especificamente pela procura ativa de informação relevante acerca do objeto da atitude. Isso supõe predisposição e postura ativa por parte do indivíduo, de modo a poder rever valores e experiências afetivas anteriores que estejam em conflito com as ações que desempenha.

O entendimento das funções das atitudes permite compreender a complexidade envolvida nas iniciativas de diversidade empreendidas pelas organizações. Embora predomine uma justificativa pela ótica da justiça social e pela relevância dos negócios, sua implementação pode engendrar resultados adversos, dependendo das diferentes atitudes dos stakeholders. Uma atitude advinda de motivação utilitarista pode estar no bojo do comportamento de empregados não beneficiados pelas iniciativas de diversidade. Pelo contrário, uma atitude proveniente de motivação simbólica pode estar subjacente no comportamento dos indivíduos, que se enquadram nos grupos de identidade social não dominante nas organizações empresariais. Dito de outra forma, o que é bom para alguns pode ser ruim para outros, mostrando a necessidade de considerar a complexidade de fazer um trade-off contínuo entre os diferentes stakeholders.

\section{Práticas de Diversidade}

O conceito de diversidade pode ser entendido de diferentes formas e apresenta diferentes focos na literatura. Para Cox (2001) diversidade refere-se à variação de identidades social e cultural entre pessoas que convivem no mesmo sistema, seja de trabalho ou outro qualquer. $\mathrm{O}$ autor sustenta que a identidade social e a cultural são afiliações pessoais como gênero, raça, origem da nacionalidade, religião, idade e especialização no trabalho, que têm "significativa influência nas experiências de vida mais importantes da pessoa” (Cox, 2001, p. 3).

As organizações, visando ampliar em seus quadros essa variedade de identidade social e cultural, buscam introduzir práticas de diversidade que espelhem a demografia da sociedade em que estão insertas. A palavra prática não raro vem acompanhada de sentido coloquial proveniente do senso comum. No entanto, vale a pena aprofundar seu entendimento na literatura, para poder esclarecer aquilo de que se fala sobre a diversidade.

A palavra prática é derivada do grego praktiké que quer dizer uso, experiência, exercício (Cunha, 1982). Ela pressupõe a execução de alguma coisa que se projetou anteriormente (Koogan \& Houaiss, 
1994). Palavras que lhes são análogas remetem à ideia de preceito, prescrição, amostra, exemplo, modelo, forma, molde, doutrina, protótipo. Isso sugere inicialmente que práticas não se definem por quaisquer atividades, mas por aquelas previamente elaboradas.

Práticas referem-se ainda a uma gama de atividades em que: (1) as pessoas se engajam em certo caminho, em certo modelo; (2) diferentes atores estão envolvidos, interagindo mutuamente e participando de perspectivas e de esquemas conceituais; isso quer dizer que pessoas dirigem práticas e práticas dirigem pessoas (Orlikowski, 2002; Wenger, McDermott, \& Snyder, 2002). Nesse sentido, não é possível falar de práticas sem que haja mais de uma pessoa compartilhando dos mesmos ideais sobre um curso de ação.

Conforme ressalta Pettigrew (1990) a descrição do termo prática envolve três dimensões: conteúdo, processo e significado. Nesse sentido uma prática pode ser identificada e documentada com base nessas dimensões.

O conteúdo diz respeito à resposta que os indivíduos dão à seguinte pergunta: que estão fazendo as pessoas? Quando há uma prática, há também alguma coisa acontecendo; pessoas estão fazendo alguma coisa juntas, em torno de um preceito ou modelo.

O processo diz respeito ao entendimento de como as pessoas fazem as coisas juntas e em que caminho elas tentam realizar essas coisas em processos, seja inter-relacionais ou interpessoais. Assim, procurando entender: Quem é envolvido e quem não é? Que interações determinam a continua reprodução e adaptação das práticas? Quem trata do que e de que forma?

Quanto ao significado, este diz respeito aos modelos de referência que as pessoas usam, a fim de fazer valer as práticas. Pessoas fazem coisas juntas, em modelo particular e compreendem o significado de suas próprias perspectivas. Desde que diferentes atores estão envolvidos no desenvolvimento de práticas, essas práticas não têm um significado, mas múltiplos significados, dependendo de quem faz, fala e age (Lave, 1993; Orlikowski, 2002).

Desse modo, práticas organizacionais voltadas para a diversidade, no contexto organizacional, referem-se, neste artigo, às atividades pelas quais pessoas compartilham de conteúdos, de processos e de significados sobre como agir diante das diferenças que há entre os indivíduos, seja de gênero, raça, nacionalidade, religião etc. ou de quaisquer dimensões visíveis ou menos visíveis, profundas ou superficiais.

\section{As Atitudes Diante de Práticas de Diversidade}

O estudo das atitudes em relação aos programas de diversidade, no contexto organizacional, torna-se relevante e justificável diante do fato de se perceber que não há, na literatura, uma expressão unânime de aceitação por parte dos indivíduos em relação ao tema. Pesquisas desenvolvidas em países avançados na adoção de programas de diversidade mostram tanto indivíduos que reagem positivamente a esses programas, como aqueles que lutam intensamente pela sua efetividade, como se pode constatar nos parágrafos seguintes.

No entanto, esses estudos voltados às atitudes dos indivíduos em relação à diversidade, encontramse dispersos, de acordo com os diferentes focos abordados em cada estudo. Por meio de vasto levantamento da literatura estrangeira nesse campo, foi possível identificar, sistematizar e categorizar as atitudes, diante da diversidade, em duas principais tendências psicológicas em relação à aceitação e duas tendências voltadas à rejeição, bem como os respectivos atores sociais envolvidos.

A Tabela 1 apresenta uma proposta de modelo teórico dessas atitudes perante as práticas organizacionais voltadas para a diversidade, representado por duas dimensões: (1) atitudes de rejeição e aceitação das práticas de diversidade; (2) os stakeholders dessa aceitação ou rejeição, ou seja, indivíduos beneficiados ou não beneficiados pelas práticas de diversidade. 
Tabela 1

Atitudes diante de práticas organizacionais voltadas para a diversidade

\begin{tabular}{|c|c|c|}
\hline & \multicolumn{1}{|c|}{$\begin{array}{c}\text { Indivíduos não beneficiados por } \\
\text { práticas de diversidade }\end{array}$} & $\begin{array}{c}\text { Indivíduos beneficiados por práticas de } \\
\text { Quadrante I }\end{array}$ \\
\hline $\begin{array}{c}\text { Atitudes de } \\
\text { aceitação }\end{array}$ & $\begin{array}{l}\text { Qceitação com base na crença na justiça } \\
\text { social }\end{array}$ & $\begin{array}{l}\text { Quadrante II } \\
\text { obtenção de ganhos }\end{array}$ \\
\hline $\begin{array}{c}\text { Atitudes de } \\
\text { rejeição }\end{array}$ & $\begin{array}{l}\text { Rejeição com base na discriminação } \\
\text { reversa }\end{array}$ & Quadrante III \\
\end{tabular}

Nota. Fonte: Dados da pesquisa

Vale ressaltar que os estudos tomados como base para a elaboração dessa proposta de modelo são de origem estadunidense. Além disso, eles abordam, essencialmente, ações afirmativas, ou seja, iniciativas de diversidade compulsórias. Se, por um lado, esses aspectos revelam uma limitação ao modelo, por outro mostram a necessidade de promover uma discussão sobre ele, na medida em que, no atual desenvolvimento dos estudos de diversidade no Brasil, pouca reflexão existe sobre o assunto, tanto no meio acadêmico quanto no ambiente profissional. Cumpre, portanto, seu papel de gerar conhecimento no campo do conhecimento. Ademais, deseja-se que essa discussão teórica encaminhe para o desenvolvimento de instrumentos válidos e validados na realidade brasileira, a partir das dimensões de diversidades mais representativas e relevantes em nossa sociedade.

A seguir, cada uma dessas dimensões de atitudes será abordada à luz de sua fundamentação teórica que a originou.

\section{Atitudes de Aceitação com Base na Justiça Social}

As atitudes de um indivíduo sob a perspectiva social são endossadas por crenças e valores compartilhados de que mulheres, minorias visíveis e pessoas portadoras de necessidades especiais são grupos que devem ser privilegiados ou favorecidos, de acordo com os recursos que têm (Beaton \& Tougas, 2001). O desenvolvimento dessas atitudes pressupõe o reconhecimento de que há certos grupos sociais de indivíduos que são mais vulneráveis a serem excluídos que outros (Lind \& Tyler, 1988).

As atitudes com base no escopo social são justificadas pela Teoria de Dominância Social que ressalta a existência de uma hierarquia de importância dos grupos sociais nas comunidades em que os indivíduos vivem. Ao se orientarem pela perspectiva da dominância social, os indivíduos exercem valores que reconhecem a não igualdade entre os grupos sociais e acabam preferindo os que estão na base da hierarquia (Sinadius \& Pratto, 1993).

Sob essas atitudes, existe a pressuposição de que alguns grupos têm características que os impossibilitam de serem avaliados e comparados a outros com base no mérito, pois ficariam em desvantagem. Isso contradiz os objetivos gerais dos programas de diversidade que procuram reconhecer o status ilegítimo de desvantagens. Por essa abordagem, os indivíduos não beneficiados pelas práticas de diversidade mostram atitudes favoráveis a essas práticas, que tendem, portanto, a apresentar menor resistência por parte do grupo dominante. Esse tipo de atitude pode sustentar uma gestão da diversidade, à luz de Liff (1997), baseada na valorização das diferenças e não na dissolução das diferenças.

A primeira abordagem foca nas diferenças baseadas nas características dos grupos sociais identificados como não dominantes e tratados como minorias, não numericamente, mas em termos de 
menor poder e recurso nas organizações, tais como mulheres, negros, pessoas com deficiências e outros grupos de diferentes identidades culturais. Por outro lado, a abordagem de gestão da diversidade baseada na dissolução das diferenças ignora as diferenças entre os indivíduos associadas à raça, gênero, idade ou estilo de vida e são também chamadas de identity-blind (Konrad \& Linnehan, 1995) ou, especificamente, de color-blind (Ellis \& Sonnenferld, 1994). Autores defensores dessa visão acreditam no princípio de igualdade de oportunidade, pelo qual se pauta no critério de competência e meritocracia. O que importa é que o individuo seja competente, efetivo, independentemente quem ele é ou quais características possui.

Os membros de atitudes favoráveis, não designados pelas práticas de diversidade, constituem atores que, a princípio, não são foco de preocupação dos tomadores de decisão sobre diversidade nas organizações. Mas é essencial conhecer suas atitudes, na medida em que, na realidade, são pessoas inseridas no mesmo ambiente cultural, atuando como gestores ou pares de membros dos grupos não dominantes e que podem resistir ou apoiar as práticas de diversidade. Essas atitudes se encontram representadas no quadrante I do modelo proposto.

\section{Atitudes de Aceitação com Base na Obtenção de Ganhos}

Estudos têm arguido que as atitudes de aceitação das práticas em prol da diversidade (especialmente as ações afirmativas) são baseados na Teoria da Privação Relativa, segundo a qual as pessoas se sentem descontentes, quando comparam suas posições com a de outros similares e descobrem que elas têm menos do que elas merecem (Runciman, 1966). Esse autor ressalta que há quatro pré-condições para a privação relativa: a pessoa não ter algo; a pessoa saber que outra pessoa tem esse algo; a pessoa querer ter esse algo e a pessoa acreditar que obter esse algo é real.

Segundo Runciman (1966), há dois tipos de privação relativa: a egoísta, causada pela não favorabilidade da posição social do indivíduo, quando comparado com outro, ou de membros de um grupo, em relação a membros de outro grupo, e a fraterna ou coletiva, causada pela não favorabilidade de um grupo, quando comparado com outro em maior vantagem.

A partir da abordagem de Runciman (1966), compreende-se que a teoria da privação relativa é egoísta, quando um indivíduo se baseia no autointeresse. Nesse caso, o indivíduo acredita que deveria, por exemplo, ter sido promovido mais rapidamente que outro; e a fraternalista é exemplificada por movimentos de grupos em relação a outros.

A teoria de privação relativa baseada no autointeresse costuma ser utilizada na literatura para justificar a atitude de aceitação das práticas de diversidade por parte dos indivíduos (Tougas, Beaton, \& Veilleux, 1991), isso porque um indivíduo que desenvolve uma atitude com base no autointeresse tenta maximizar ganhos e prevenir perdas individuais. No entanto, estudos empíricos não confirmam que o autointeresse desempenhe um papel importante na aceitação dos indivíduos a essas práticas (Kinder, 1986; Mcclendon \& Pestello, 1983). Veilleux e Tougas (1989) ressaltam que reações de interesse dos indivíduos às práticas de diversidade emanam mais dos interesses de grupos e das posições desses na sociedade do que de preocupações pessoais, particulares. O autor justifica-se com base na teoria de privação relativa fraterna ou coletiva (Runciman, 1966).

Segundo Tougas et al. (1991) são as relações intergrupais que promovem estratégias para melhorar a situação coletiva dos membros de grupos sociais que estão em desvantagem, de modo que:

Um membro de um grupo minoritário que sofre de desvantagem utiliza-se primeiro de estratégias de mobilidade individual para melhorar a sua condição. Contudo, quando falha nesse objetivo, ele torna-se convencido de que seu status é coletivamente determinado e ilegítimo, se considerado particularmente. A partir desse ponto, ele passa então a acreditar que estratégias coletivas têm precedentes sobre as individuais (Tougas et al. 1991, p. 764).

Tendo em vista que as práticas de diversidade, especialmente as baseadas em modelos de gestão (Hanashiro \& Godoy, 2004b), se propõem eliminar barreiras para o desenvolvimento de indivíduos que pertençam a grupos minoritários, bem como desenvolver tratamentos diferenciados para aumentar 
a representação desses grupos nas organizações, torna-se plausível que membros de grupos minoritários adotem atitudes de aceitação desses programas, visando a esses fins.

Em síntese, fundamentado na teoria acima apresentada, os indivíduos supostamente designados pelas práticas de diversidade demonstram atitudes favoráveis a elas, com base na obtenção de ganhos por meio da adesão ao interesse coletivo, já que individualmente suas conquistas podem ser limitadas. Esses pressupostos caracterizam o Quadrante II do modelo.

\section{Atitudes de Rejeição com Base na Discriminação Reversa}

As atitudes que definem esse fator são as decorrentes da percepção dos grupos de indivíduos que não são designados ou beneficiados pelas práticas de diversidade. A importância em ressaltar essas atitudes está em compreender que esses indivíduos enxergam tais práticas como ameaça (Beaton \& Tougas, 2001).

Na literatura, essas atitudes são identificadas por fortes resistências de grupos de indivíduos aos programas de diversidade, normalmente homens brancos, porque se sentem vítimas, discriminados ou desfavorecidos em detrimento de grupos de minorias, principalmente em períodos de recessão de empregos (Fair Employment Pratice Guidelines, 2004, p. 1). Essa rejeição, quando operacionalizada, é denominada na literatura de “discriminação reversa”.

A rejeição às práticas de diversidade pelos homens brancos já foi constatada em estudos realizados em diferentes países, principalmente diante dos programas legais (Kidder, Lankau, Chrobot-Mason, Mollica, \& Friedman, 2004; Leck \& Saunders, 1996; Richard \& Kirby, 1997).

Wilson (2006) realizou uma pesquisa na intenção de descobrir se a rejeição dos homens brancos às práticas de diversidade era decorrente de uma predisposição negativa aos programas que dão preferência a categorias de grupos por si ou se ela estava relacionada com predisposições negativas anteriores (preconceitos) em relação a negros.

Os dados para a realização desta pesquisa foram obtidos por meio do General Social Survey (Davis e Smith, 2003), que avalia as atitudes dos indivíduos em relação às preferências de contratação e de promoção das organizações em relação a negros e mulheres. A amostra foi de 325 homens e 405 mulheres. Wilson (2006) descobriu que as atitudes negativas de brancos são expressas tanto em relação aos negros, quanto a mulheres e similarmente aos programas de diversidade que dão preferência a grupos em geral. Embora o autor aponte o tamanho da amostra como limitação da pesquisa, ela dá indícios de que essas atitudes são decorrentes de um novo tipo de racismo originado com os programas de diversidade.

Wilson (2006) conclui que as atitudes em relação aos negros se baseiam em um racismo tradicional baseado na velha pressuposição de que os negros pertencem a uma raça biológica inferior. No entanto, ele ressalta que as atitudes em relação às práticas de diversidade são baseadas em nova forma de racismo, denominado de racismo simbólico, ou seja, atitude que revela predisposição negativa de brancos em relação a políticas sociais de proteção ou que dão preferência a categorias de grupos de indivíduos em geral e não só a negros (Tarman \& Sears, 2005). Tal atitude inclui ideologia política, atitude em direção ao papel do governo, igualitarismo, estratificações ideológicas e assuntos relacionados à justiça (Federico \& Sinadius, 2002; Kinder \& Sears, 1981, Kluegel \& Smith, 1983).

Ao relacionar atitudes e diversidade o estudo de Wilson (2006) revela, por fim, que as atitudes desfavoráveis dos brancos em relação aos programas de diversidade estão mais baseadas nos aspectos cognitivos, mais especialmente em preconceitos, do que em aspectos afetivos ou comportamentais.

A fundamentação teórica anteriormente desenvolvida dá suporte para a formulação do Quadrante III, que diz respeito às atitudes de pessoas que não são atores sociais diretamente envolvidos pelas práticas de diversidade, mas que podem resistir a elas, pela predisposição ao preconceito simbólico e à discriminação reversa. 


\section{Atitudes de Rejeição com Base no Receio ao Estigma}

As atitudes em face das práticas de diversidade também podem ser de rejeição, mesmo pelos grupos de indivíduos designados ou beneficiados. Alguns estudos empíricos realizados nos Estados Unidos constataram que práticas baseadas em preceitos legais de diversidade (Ações Afirmativas) costumam estigmatizar os indivíduos beneficiados como sendo menos qualificados ou incompetentes; isso mais atrapalha do que ajuda, segundo alguns autores (Heilman, Block, \& Lucas,1992; Nacoste, 1992).

As atitudes sob essa perspectiva são baseadas na crença de que os indivíduos contratados com base em preceitos legais de diversidade são menos qualificados ou são incompetentes, porque tais programas não atribuem a qualificação como critério para contratá-los, como ocorre em contratações regulares (Keeley \& Michela, 1980). Isso pode minimizar o potencial dos indivíduos submetidos a esses programas. Mesmo que os indivíduos tenham competência, eles não serão vistos por outros sob esse prisma. Consequentemente, as próprias pessoas contratadas passam a ter receio de uma conotação negativa de suas capacidades e, com isso, paradoxalmente, desenvolvem atitudes contrárias às práticas que as beneficiaram na contratação.

Os resultados de pesquisa realizada por Heilman e Alcott (2001) sugerem que o estigma de incompetência, atribuído aos indivíduos beneficiados pelas práticas de diversidade, que não priorizam a qualificação como critério de avaliação, se origina na contratação, mas persiste durante o desenvolvimento da carreira deles na organização. Esse estigma enviesa o processo de tomada de decisão sobre promoções por parte dos dirigentes, que os concebem como pessoas menos qualificadas em relação a outros. No entanto, os autores observam que o estigma de incompetência somente ocorre, quando os grupos de minoria já possuem um estereótipo negativo, pois esse estigma não acontece com os americanos descendentes de asiáticos.

Uma gestão efetiva da diversidade, para essa perspectiva, poderia obter melhor resultado pela perspectiva da dissolução da diversidade (Liff, 1997; Pereira \& Hanashiro, 2007), baseada exclusivamente na competência dos grupos considerados não dominantes nas organizações e não pela valorização da diversidade, ou seja, pela sua pertença a determinado grupo de identidade social. Essas atitudes de rejeição às práticas de diversidade constituem o quadrante IV.

\section{CONSIDERAÇÕES FINAIS}

Diversas são as atitudes das pessoas diante de práticas de diversidade e diversos são os grupos de identidade social que hoje fazem parte de uma categoria menos silenciosa que outrora, mas ainda silenciada pelo poder dos grupos dominantes. Dar o legítimo destaque às ditas minorias significa desconstruir uma lógica linear de que as práticas organizacionais são feitas pelos grupos dominantes e para eles. A sociedade está se tornando mais heterogênea; isso não é fato isolado, mas fenômeno global e inexorável. Portanto, as organizações que buscam sobreviver num mundo cada vez mais competitivo precisarão lidar com o desafio da complexidade do hibridismo cultural que caracterizará as organizações multiculturais. No entanto, o foco deste ensaio não foi defender o ponto de vista estratégico da diversidade, discutindo se suas práticas conduzem a uma vantagem competitiva para as empresas. Seu principal interesse foi o de argumentar que essas práticas podem provocar diferentes reações nos diferentes indivíduos envolvidos direta ou indiretamente e que essa falta de unanimidade pode afetar os resultados dessas práticas. Há uma tendência de os estudos considerarem preponderantemente os potenciais beneficiários dessas práticas, ocultando as reações dos outros atores sociais. O conhecimento das reações destes indivíduos, assim como as dos demais, é de fundamental importância para a implantação, desenvolvimento de programas ou modelos mais efetivos de gestão da diversidade.

Nesse sentido, propõe-se um modelo teórico das atitudes diante das práticas de diversidade sustentado em duas dimensões. A primeira mostra duas predisposições, uma de aceitação e outra de 
rejeição. E a outra dimensão identifica os que são por elas afetados positiva ou negativamente. Como resultado o modelo apresenta quatro quadrantes: (I) atitudes de aceitação com base na justiça social; (II) atitudes de aceitação dos stakeholers com base na obtenção de ganhos; (III) atitudes de rejeição com base na discriminação reversa; e (IV) atitudes de rejeição com base no receio do estigma.

Diversidade é fenômeno complexo. Sua compreensão requer uma base teórica proveniente de várias áreas do conhecimento e é de natureza multidimensional (todos nós temos várias identidades cultural e social, ou seja, somos diversos em diferentes dimensões, mais visíveis ou menos visíveis). Além disso, caracteriza-se como fenômeno que ocorre no nível individual e didático, no que diz respeito à relação de supervisor e subordinado (Silveira \& Hanashiro, 2007), grupal, no âmbito dos grupos de trabalho (Hanashiro \& Queiroz, 2005) e organizacional (políticas e procedimentos em Hanahsiro \& Godoy, 2004). O modelo proposto foca no nível individual, pois trata das predisposições individuais perante as práticas de diversidade. Não tem a pretensão, portanto, de explicar o fenômeno diversidade em todas as suas facetas. Mas, certamente, procura contribuir para o aprofundamento teórico que se encontra em fase ainda incipiente. Entender o que influencia o fenômeno da diversidade, como ocorre essa influência e seu resultado são apenas alguns passos a serem aprendidos.

Apesar dessa potencial contribuição, é importante pontuar que o modelo precisa ser testado empiricamente para proporcionar efetivo aprofundamento teórico. Sua formulação conceitual sustentase no mainstream estadunidense, cuja realidade social e legal, quanto à diversidade, difere da brasileira. As ações afirmativas e oportunidades iguais de trabalho constituem mecanismos de promoção da diversidade nos Estados Unidos há quase quatro décadas e vêm promovendo uma força de trabalho mais diversificada. Ainda assim, como já foi comentado anteriormente, poucos estudos espelham essa preocupação com as atitudes das pessoas perante as práticas de diversidade. Por essa razão, acredita-se que o estudo fornece uma contribuição, ao sistematizar essas atitudes, lançando luzes para outras perspectivas de estudo em diversidade. Considerando essa importância, as autoras desenvolveram uma escala para mensurar as atitudes voltadas à diversidade, que se encontra em fase de validação em território nacional. Seu resultado provavelmente possibilitará dar respostas a algumas indagações: será que essas dimensões estão presentes na realidade brasileira tal como na construção teórica? Existe alguma predominante? Será que as dimensões diferem por região geográfica? Será que o fato de uma empresa possuir políticas formais de diversidade afeta essas atitudes? Em que medida essas dimensões diferem de acordo com as características demográficas?

Por fim, vale ressaltar que o conhecimento dessas atitudes, dos grupos não dominantes (“diversos”) e dominantes, talvez permita desenvolver práticas de diversidade mais efetivas e menos homogeneizantes, reconhecendo as diferenças individuais e entendendo que diversidade diz respeito à variedade de identidades sociais e culturais, como declara Cox (2001), e não apenas para aqueles grupos considerados não dominantes nas organizações.

Artigo recebido em 04.03.2009. Aprovado em 19.10.2009.

\section{REFERÊNCIAS BIBLIOGRÁFICAS}

Abbagnano, N. (1982). Dicionário de filosofia. São Paulo: Mestre Jou.

Allport, G. W. (1935). Attitudes. In C. Murchinson (Ed.), A handbook of social psychology (pp. 798844). Worcester, Mass: Clark University Press.

Aronson, E., Wilson, T. D., \& Akert, R. M. (2002). Psicologia social (Cap. 7). Rio de Janeiro: LTC.

Beaton, A. M., \& Tougas, F. (2001) Reactions to affirmative action: group membership and social justice. Social Justice Research, 14(1), 61-78. 
Bond, M. A., \& Pyle, J. L. (1998). Diversity dilemmas at work. Journal of Management Inquiry, 7(3), 252-269.

Cox, T., Jr. (1991). The multicultural organization. Academy of Management Executive, 5(2), 34-47.

Cox, T., Jr. (2001). Creating the multicultural organization: a strategy for capturing the power of diversity. Jossey-Bass: San Francisco.

Cox, T., Jr., \& Blake, S. (1991). Managing cultural diversity: implications for organizational competitiveness. Academy of Management Executive, 5(3), 45-56.

Cunha, A. G. (1982). Dicionário etimológico. Rio de Janeiro: Nova Fronteira.

Davis, J. A., \& Smith, T. W. (2003). General social surveys (1972-2002). Chicago: National Opinion Research Center.

Eagly, A. H., \& Chaiken, S. (1993). The psychology of attitudes. Fort Worth, TX: Harcourt, Brace, Jovanovich.

Ellis, C., \& Sonnenfeld, J. A. (1994). Diverse approaches to managing diversity. Human Resource management, 33(1), 79-109.

Eron, A. M. V. (1995). Ways to assess diversity success. Human Resource Magazine, 40(8), 51.

Fazio, R. H., \& Williams, C. J. (1986). Attitude accessibility as a moderator of the attitude-perception and attitude-behavior relations: an investigation of the 1984 presidential election. Journal of Personality and Social Psychology, 51(3), 505-514.

Federico, C. M., \& Sinadius, J. (2002). Sophistication and the antecedents of white racial policy attitudes: racism, ideology and affirmative action in America. The Public Opinion Quarterly, 66(2), 145-76.

Festinger, L. (1957). A theory of cognitive dissonance, Evaston: Row, Peterson.

FishbeiN, M., \& Ajzen, I. (1975). Belief, attitude, intention and behavior: an introduction to theory and research. Massachusetts: Addison-Wesley.

Hanashiro, D. M. M., \& Godoy, A. S. (2004b). Estudos em diversidade: reflexões teóricas e evidências práticas. Anais do Encontro de Estudos Organizacionais, Atibaia, São Paulo, Brasil, 3.

Hanashiro, D. M. M., \& Godoy, A. S. (2004a, setembro). Um preâmbulo à gestão da diversidade: da teoria à prática. Anais do Encontro Nacional da Associação Nacional de Pós-Graduação e Pesquisa em Administração, Curitiba, PR, Brasil, 28.

Hanashiro, D. M. M., \& Queiroz, R. C. O (2005, setembro). O efeito da diversidade no desempenho dos times de trabalho: um Trade-off entre homogeneidade e heterogeneidade? Anais do Encontro Nacional da Associação Nacional de Pós-Graduação e Pesquisa em Administração, Brasília, DF, Brasil, 29.

Heider, F. (1958). The psychology of international relation. New York: John Wiley e Sons, Inc., Publishers.

Heilman, M. E., \& Alcott, V. B. (2001). What I think you think of me: women's reactions to being viewed as beneficiaries of preferential selection. Journal of Applied Psychology, 86(4), 574-82.

Heilman, M. E., Block, C. J., \& Lucas, J. A. (1992). Presumed incompetent? Stigmatization and affirmative action efforts. Journal of Applied Psychology, 77(4), 536-544. 
Holzer, H., \& Neumark, D. (2000). Assessing affirmative action. Journal of Economic Literature, 38(3), 483-568.

Ivancevich, J. M., \& Gilbert, J. A. (2000). Diversity management time for a new approach. Public Personnel Management, 29(1), 75-92.

Katz, D. (1960). The Functional approach to the study of attitude change. Public Opinion Quarterly, 24(2), 163-204.

Keeley, H. H., \& Michela, J. L. (1980). Attribution theory and research. Annual Review of Psychology, 31, 457-501

Kidder, D. L., Lankau, M. J., Chrobot-Mason, D., Mollica, K. A., \& Friedman, R. A. (2004). Backlash toward diversity initiatives: examining the impact of diversity program justification, personal and group outcomes. International Journal of Conflict Management, 15(1), 77-102.

Kinder, D. R. (1986). The continuing America dilemma: white resistance to racial change 40 years after Myrdal. Journal of Social Issues, 42(2), 151-171.

Kinder, D. R., \& Sears, D. O. (1981). Prejudice and politics: symbolic racism versus racial threats to the good life. Journal of Personality and Social Psychology, 40(3), 414-431.

Kluegel, J. R., \& Smith, E. R. (1983). Affirmative action attitudes: effects of self-interest, racial affect, and stratification beliefs on white's views. Social Forbes, 61(3), 797-824.

Kochan, T., Bezrukova, K., Ely, R., Jackson, S., Joshi, A., Jehn, K., Leonard, J., Levine, D., \& Thomas, D. (2003). The effects of diversity on business performance: report of the diversity research network. Human Resource Management, 42(1), 3-21.

Konrad, A. M., \& Linnehan, F. (1995). Formalized HRM structures: coordinating equal employment opportunity or concealing organizational practices? Academy of Management Journal, 38(3), 787-820.

Koogan, A., \& Houaiss, A. (1994). Enciclopédia e dicionário ilustrado. Rio de Janeiro: Ed. Delta.

Lave, J. (1993). The practice of leaning. In S. Chaiklin \& J. Lave (Ed.), Understanding practice: perspectives on activity on context (pp. 3-34). Cambridge, UK: Cambridge University.

Leck, J. D., \& Saunders, D. M. (1996). Affirmative actions programs: an organizational justice perspective. Journal of Organizational Behavior, 17(1), 79-89.

Liff, S. (1997). Two rotes to managing diversity: individual differences or social group characterisitics. Employee Relations, 19(1), 11-26.

Lima, L. P. (2000). Atitudes: Estrutura e mudança. In J. Vala \& M. B. Monteiro (Eds.), Psicologia social (pp. 187-225). Lisboa: Fundação Calouste Gulbenkian.

Lind, E. A., \& Tyler, T. R. (1988). The social psychology of procedural justice. New York: Plenum Press.

Mcclendon, M. J., \& Pestello, F. P. (1983). Self-Interest and public policy attitude formation: busing for school desegregation. Social Focus, 16, 1-12.

Mor Barak, M. E. (2005). Managing diversity: toward a globally inclusive workplace. Thousand Oak: Sage Publications.

Nacoste, R. B. (1992). Toward a psychological ecology of affirmative action. Social Justice Research, 5(3), 269-289. 
Nkomo, S. M., \& Cox, T., Jr. (1986). Differential performance appraisal criteria: a field study of black and white managers. Group \& Organization Studies, 11(1-2), 101-120.

Orlikowski, W. J. (2002). Knowing in practice: enacting a collective capability in distributed organizing. Organization Science, 13(3), 249-273.

Pereira, J. B. C., \& Hanashiro, D. M. M. (2007, setembro). Gestão da diversidade: uma questão de valorização ou de dissolução das diferenças? Anais do Encontro Nacional da Associação Nacional de Pós-Graduação e Pesquisa em Administração, Rio de Janeiro, RJ, Brasil, 31.

Pettigrew, A. (1990). Longitudinal Field Research on Change: Theory and practice. Organization Science, 1(3), 267-292.

Richard, O. C., \& Kirby S. L. (1997). Attitudes of white American male students toward work force diversity programs. The Journal of Social Psychology, 137(6), 784-786.

Rokeach, M. (1968). Beliefs, attitudes and Values. San Francisco: Jassey-Bass.

Runciman, W. G. (1966). Relative deprivation and social justice: a study of attitudes to social inequality in twentieth-century. England: University of California Press.

Silveira, N. S. P., \& Hanashiro, D. M. M. (2007, setembro). Narciso acha feio o que não é espelho: o discurso da diversidade e a prática da similaridade. Anais do Encontro Nacional da Associação Nacional de Pós-Graduação e Pesquisa em Administração, Rio de Janeiro, RJ, Brasil, 31.

Sidanius, J., \& Pratto, F. (1993). The dynamics of social dominance and the inevitability of oppression. In P. Sniderman \& P. E. Tetlock (Eds.), Prejudice, politics, and race in America today (pp. 173-211). Stanford, Califórnia: Stanford University Press.

Tarman, C., \& Sears, D. O. (2005). The conceptualization and measurement of symbolic racism. The Journal of Politics, 67(3), 731-761.

Thomas, D. A., \& Ely, R. J. (1996). Making differences matter: a new paradigm for managing diversity. In The Jossey-Bass reader on educational leadership (Chap. 19, pp. 197-210). San Francisco: Jossey-Bass.

Tougas, F., Beaton, A., \& Veilleux, F. (1991). Why women approve affirmative action: the study of a predictive model. International Journal of Psychology, 26(6), 761-776.

Veilleux, F., \& Tougas, F. (1989). Male acceptance of affirmative action programs for women: the results of altruistic or egoistical motives? International Journal of Psychology, 24(4), 485-496.

What is Reverse Discrimination and how do you prove it? (2004). Fair Employment Practice Guidelines, (591), 1-4.

Wenger, E., McDermott, R., \& Snyder, W. M. (2002). Cultivating communities of practice: a guide to managing knowledge (Hardcover). Boston: Harvard Business School Press.

Wetling, R. M., \& Palma-Rivas, N., (2000). Current status of diversity initiatives in selected multinational corporation. Human Resource Develpement Quartely, 11(1), 35-60.

Wilson, T. C. (2006).Whites' opposition to affirmative action: rejection of group-based preferences as well as rejection of blacks. Social Forbes, 85(1), 111-120. 